\title{
PRODUÇÃO DE MAQUETE DE RELEVO COMO RECURSO DIDÁTICO- METODOLÓGICO NO ENSINO DA CARTOGRAFIA EM GEOGRAFIA
}

\author{
Danielli Batistella ${ }^{(a)}$, Nair Sanzovo Pivatto ${ }^{(b)}$ \\ (a) Departamento de Agrimensura/Universidade Tecnológica Federal do Paraná, batistella@utfpr.edu.br \\ (b) Departamento de Humanas/ Universidade Tecnológica Federal do Paraná, pivatto@utfpr.edu.br \\ EIXO: GEOGRAFIA FÍSICA - CURRÍCULO, FORMAÇÃO E PRÁTICAS DE ENSINO
}

\begin{abstract}
Resumo
O presente trabalho tem como objetivo apresentar a experiência didático-metodológica, realizada no curso Técnico Integrado de Agrimensura da UTFPR, Câmpus Pato Branco, a partir da construção de uma maquete do relevo do município de Pato Branco, estado do Paraná, no ensino da cartografia. A construção de maquete a partir da abordagem sistêmica, que percebe o espaço como um todo e não em suas partes, como na abordagem tradicional, tem como finalidade facilitar o processo de ensino-aprendizagem dos estudantes de educação básica durante as aulas de geografia, pois permite a visualização tridimensional de uma determinada área da superfície terrestre, que somente é percebida de forma limitada em mapas bidimensionais.
\end{abstract}

Palavras chave: relevo, cartografia, prática de ensino.

\section{Introdução}

Para a construção de maquete é necessário percepção do ambiente como um todo e sendo assim como um sistema, sob a forma de modelo, ou seja, a maquete como sendo um modelo é um conjunto organizado de dados aceitos como correspondentes às estruturas de objetos e atributos ambientais percebidos. Existem muitos tipos de modelos de percepção da realidade (XAVIER DA SILVA, 1982), desde os religiosos baseados em dogmas, passando pelos artísticos até os numerosos modelos ditos científicos, ancorados na lógica. Para fins científicos ou de aprendizagem, não é suficiente gerar, identificar e classificar dados ambientais, pois estes podem constituir uma expressão integrada de uma situação ambiental ocorrente sobre a superfície da Terra que, como tal, necessita ser analisada.

Para a análise ambiental tanto quanto para o pesquisador ou para o educando, é necessária a capacidade de decompor o ambiente em suas partes básicas, o que requer a preservação das partes, criando a possiblidade de alcançar um retrato único e integrado da situação ambiental que está representada no modelo construído - a maquete. Também numa perspectiva semiótica podemos dizer que os meios não são uma janela aberta sobre o mundo, através da qual o recebemos, numa absoluta coincidência entre a representação e a realidade, mas de que os meios disponibilizam uma representação codificada, simbólica de uma realidade, constituindo-se como uma leitura e interpretação particular e subjetiva de que o autor do meio elaborou e disponibilizou dessa mesma realidade (MASTERMAN, 1993). 
Maquetes por serem representações cartográficas tridimensionais têm altura, largura e profundidade e, como tal, constituem um exercício completo de modelagem. É uma das formas práticas da abordagem sistêmica, uma vez que não representam um fim didático, mas um meio didático na leitura de vários elementos que compõem o espaço, entre eles conceitos em geomorfologia - relevo, bacias hidrográficas, por exemplo.

A abordagem sistêmica postula que todos os elementos (estruturas) se influenciam e são influenciados reciprocamente. Assim, a construção de um modelo (maquete) possibilita ao aluno extrair da realidade características ou relações importantes e representá-las de maneira simplificada, ou seja, tem-se aí a possibilidade de criação de estruturas de dados particulares que se destinam a representar sistemas, permitindo seu estudo (PIVATTO, 2013)

Para Haggett e Chorley, citados por Christofoletti (2002), a construção de modelos implica uma atitude altamente seletiva quanto às informações, isto é, definem o modelo como aproximação seletiva que pela eliminação dos detalhes acidentais permite salientar alguns aspectos fundamentais ou interessantes do mundo real sob forma generalizada.

Um modelo é sempre uma simplificação da realidade, ou seja, a visão que temos dessa realidade (BRUNET, 1980), é, por conseguinte, a representação da realidade e não a realidade. Nessa perspectiva, o objetivo da simplificação da realidade é operacional e engloba a ação, a previsão e a explicação e o modelo é uma representação, portanto, um constructo, isto é, construção puramente mental, criada a partir de elementos mais simples para ser parte de uma teoria (HOUAISS, 2001).

A abordagem sistêmica e o uso de modelo servem como instrumento conceitual que lhe facilita tratar dos conjuntos complexos, como a organização espacial. A preocupação em focalizar as questões geográficas sob a perspectiva sistêmica é representar características que favorecem e dinamizam o desenvolvimento da Geografia.

A abordagem sistêmica, por meio de modelos, pode ser considerada como estruturação sequencial de ideias relacionadas com o funcionamento do sistema, a fim de torná-lo compreensível e expressar as relações entre os diversos componentes.

Para Xavier da Silva (2001), qualquer entidade percebida - inclusive a própria realidade concebida como um modelo, isto é, como um sistema, pode ter seus limites de ocorrência examinados e definidos, ser decomposto em partes componentes (as quais podem vir a ser consideradas sistemas por si próprias, e, por isso, ter investigadas as relações funcionais que interligam suas partes componentes e consideradas, também, suas relações com outras entidades e eventos externos (outros sistemas). O modelo é um 
instrumento de trabalho que deve ser utilizado na representação e análise de diferentes sistemas espaciais, entre os quais, conjuntos geomorfológicos, hidrográficas, ocupação humana etc.

Considerando o espaço como conjunto de sistemas, e, deslocando-o para o ponto de vista da realidade, esta realidade passa a ser encarada como um conjunto de estruturas perceptíveis, tal como um sistema geomorfológico de determinada área. Essas estruturas são modelos (XAVIER DA SILVA, 2001) e podem assumir diversas formas e níveis de complexidade. Assim, construir um modelo possibilita ao modelista pesquisar e extrair da realidade características ou relações importantes e representá-las de maneira simplificada, ou seja, tem-se aí a possibilidade de criação de estruturas de dados particulares que se destinam a representar sistemas e permitir seu estudo.

Dessa maneira poderá ser representada cada parte do sistema (estrutura) observando-a e analisando-a como um todo e como ela está ligada a cada parte do todo. A maquete aparece então como um processo de restituição do concreto (relevo) a partir de uma abstração (curva de nível), centrando-se aí sua real utilidade, complementada em diversos usos a partir deste modelo concreto trabalhado pelos alunos. (BROMBERG, P.; GIRARDI, G.; SIMIELLI, M.H.R.,1991).

\section{Objetivos}

O presente trabalho consiste em apresentar a experiência didático-metodológica, realizada no curso Técnico Integrado de Agrimensura da UTFPR, Câmpus Pato Branco, a partir da construção da maquete do relevo do município de Pato Branco, estado do Paraná, no ensino da cartografia. A construção da maquete a partir da abordagem sistêmica teve por objetivo facilitar o processo de ensino-aprendizagem dos estudantes de educação básica durante as aulas de geografia, pois permite a visualização tridimensional de uma determinada área da superfície terrestre, que somente é percebida de forma limitada em mapas bidimensionais.

\section{Metodologias}

Para a construção da maquete do município foram utilizadas as curvas de nível de 500 a 900 metros de altitude, com equidistância de 100 metros, extraídas das cartas topográficas SG-22-Y-A-III-1, SG-22-YA-III-2, SG-22-Y-A-III-3, SG-22-V-C-VI-4 e SG-22-Y-A-III-4 do ITCG (Instituto de Terras, Cartografia e Geociências) do estado do Paraná na escala 1:50.000. Foi realizado o georreferenciamento das cartas topográficas no programa ArcGIS 10 e as curvas de nível vetorizadas foram impressas sobre papel sulfite e transpostas em cinco placas de isopor de $1 \mathrm{~cm}$ para a etapa do recorte. Na sequência foi realizada a 


\section{OS DESAFIOS DA GEOGRAFIA FÍSICA NA FRONTEIRA DO CONHECIMENTO \\ Instituto de Geociências - Unicamp \\ Campinas - SP \\ 28 de Junho à 02 de Julho de 2017}

sobreposição e colagem das placas recortadas, o recobrimento com massa corrida e o acabamento. A etapa do recorte das placas de isopor pode ser visualizada na Figura 1.

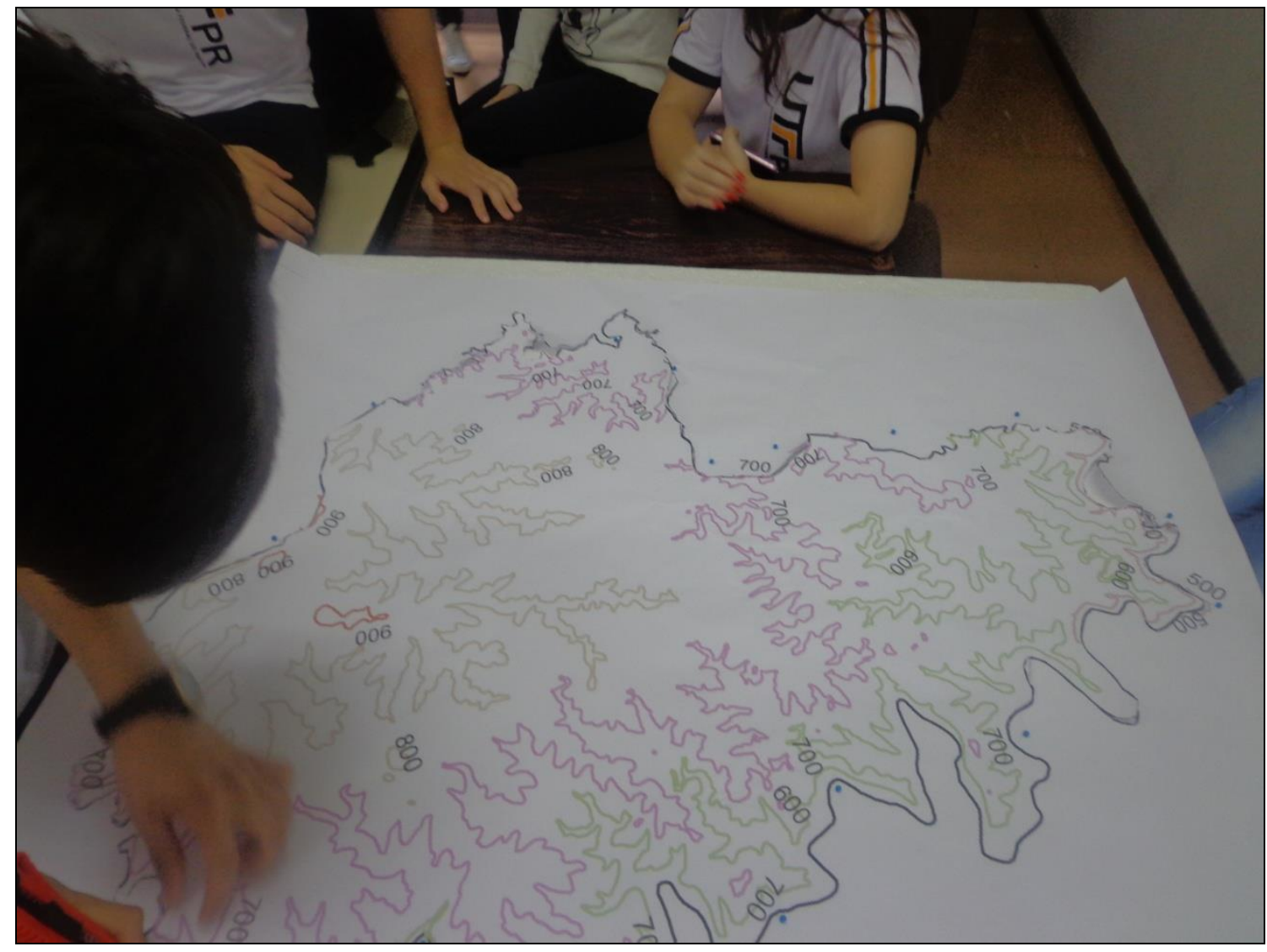

Figura 1 - Recorte das placas de isopor pelos alunos

$\mathrm{Na}$ etapa do acabamento utilizou-se de cores hipsométricas para adequar à linguagem cartográfica, que variaram as áreas, sendo as curvas mais baixas em verde, depois em amarelo, laranja e marrom para as mais altas.

Para melhoria das informações morfométricas, representaram-se também os principais rios, assim o aluno pôde perceber além dos elementos e formas do relevo como divisor de água, talvegue, patamar e topos, e visualizar também a localização das nascentes dos principais rios do município, a orientação das vertentes e sua foz. As etapas do desenvolvimento da maquete podem ser visualizadas no fluxograma a seguir. 
Campinas - SP

de Geografia Física

28 de Junho à 02 de Julho de 2017

\begin{tabular}{|c|c|c|c|}
\hline $\begin{array}{c}\text { Cartas Topográficas } \\
1 / 50.000\end{array}$ & $\begin{array}{c}\text { Extraçào das curvas de } \\
\text { nivel e rios }\end{array}$ & Plotagem & $\begin{array}{l}\text { Transposição das } \\
\text { curvas de nivel para a } \\
\text { placas de isopor }\end{array}$ \\
\hline
\end{tabular}

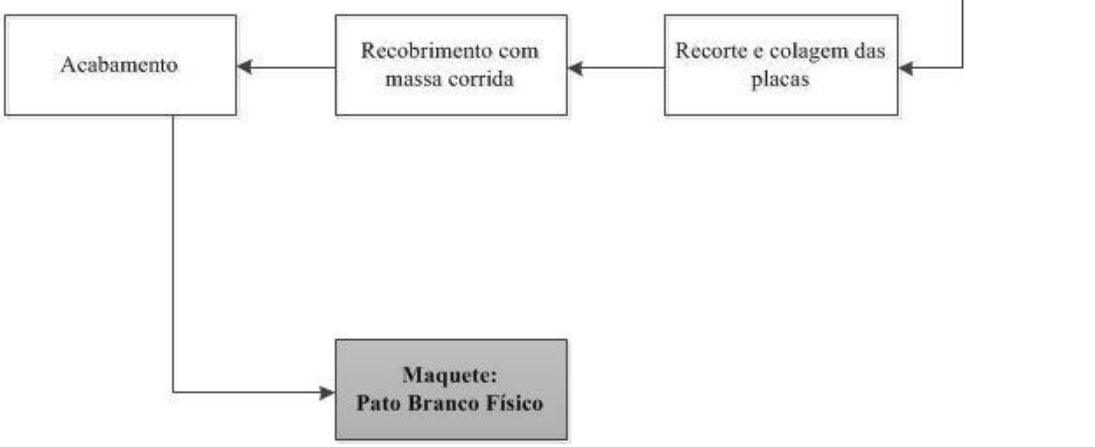

Figura 2 - Etapas de elaboração da maquete

\section{Resultados}

A construção da maquete que representa Pato Branco físico, constituído por classes de altitudes e pelos rios, permitiu ao aluno visualizar uma parte do todo dentro da perspectiva sistêmica. Este recurso didáticopedagógico possibilitou ao estudante dominar conceitos espaciais e as formas de representações do espaço geográfico. A maquete finalizada é apresentada na Figura 3.

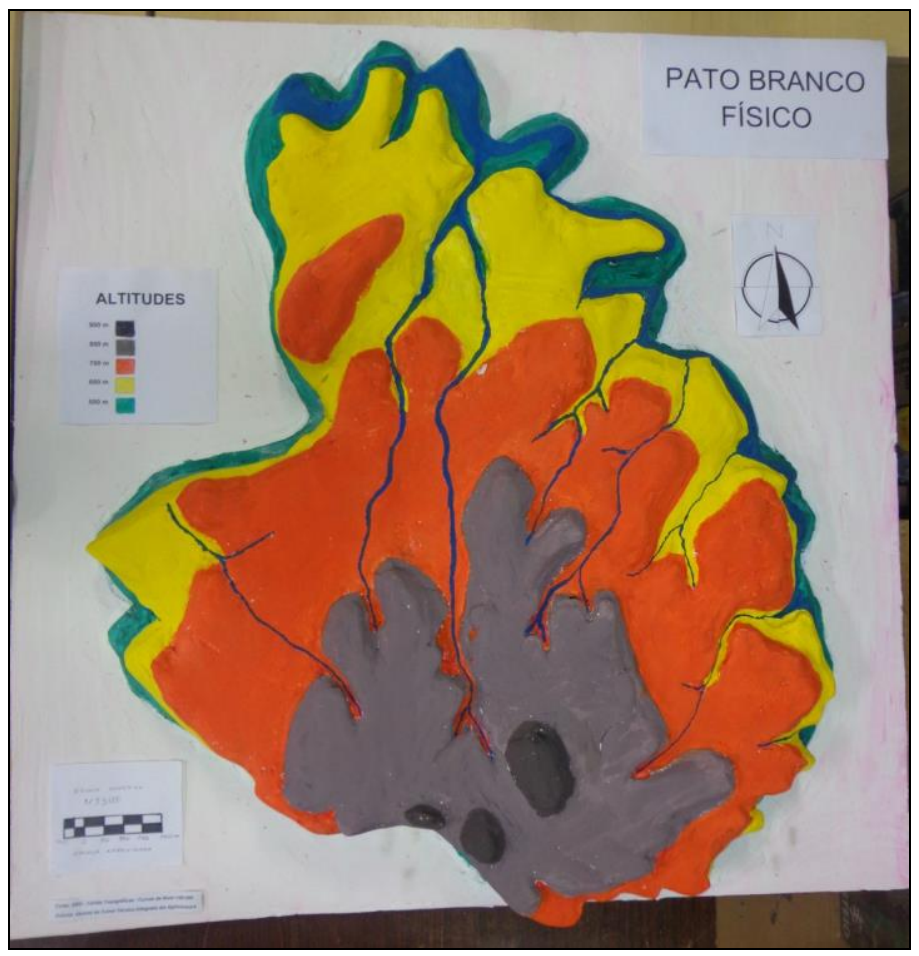

Figura 3 - Maquete finalizada 


\section{Considerações finais}

A maquete contribuiu para que os alunos tivessem uma percepção tridimensional do relevo, o que deixou visível as formas topográficas e a dinâmica dos rios, situação um tanto difícil de visualizar em mapas bidimensionais através das curvas de nível. Essa atividade quando elaborada pelos alunos, melhora significativamente a leitura e interpretação de cartas topográficas e dos mapas físicos, bem como é excelente recurso didático disponível ao professor ao demonstrar aos alunos, as forma de relevo as quais ficarão mais próximas com a realidade que se quer apresentar.

\section{REFERENCIAS}

BRUNET, R. La Compositino dês modeles dans l'analyse Spatiale L'Esaace. Geographique. no 4, p. 253-265, 1980.

BROMBERG, P.; GIRARDI, G.; SIMIELLI, M.H.R. Do plano ao tridimensional: a maquete como recurso didático. Boletim Paulista de Geografia, nº 70, p. 5-30, 1991.

BROMBERG, P.; GIRARDI, G.; SIMIELLI, M.H.R. Maquete de relevo: um recurso didático tridimensional. Boletim Paulista de Geografia, nº 87, p., 2008.

CHRISTOLETTI, A. Modelagem de Sistemas Ambientais. São Paulo: Edgar Blücker Ltda, 2002.

HOUAISS. Dicionário, 2001.

Instituto de Terras, Cartografia e Geociências - ITCG. Cartas topográficas rasterizadas. 22 mai. 2012. Disponível em: < http://www.itcg.pr.gov.br/modules/conteudo/conteudo.php?conteudo=47> Acesso em: 22 mai. 2012.

MASTERMAN, Len. La Enseñanza de los Médios de Comunicación. Madrid: Ediciones de la Torre, 1993.

PIVATTO, N.S. O Paraná e suas regiões - uma análise territorial a partir da modelização. Tese (Doutorado em Geografia) Programa de Pós-Graduação em Geografia da Universidade Federal do Paraná. Curitiba, 2013.

XAVIER DA SILVA, J. Geoprocessamento para análise ambiental. Rio de Janeiro: D5 Produção Gráfica, 2001. Disponível em < htt://www.lageop.ufrj.br>. Acesso em: 02 fev. 2009. 